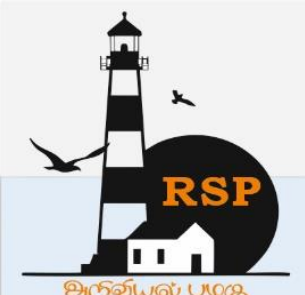

\title{
Experimental Investigation of EDM Process Parameters on
}

\section{Aluminum Nano composite using Taguchi Technique}

Soundararajan. $R^{1}$, Hariprasath. $V^{2}$, Keerthivasan. $R^{3}$, Muthukumar. $S^{4}$, Naveenkumar. $C^{5}$

${ }^{1}$ Assistant Professor, Mechanical Engineering, Mahendra Engineering College, Namakkal, Tamilnadu, India.

2.3.4.5 UG Student, Mechanical Engineering, Mahendra Engineering College, Namakkal. Tamilnadu, India.

${ }^{1}$ soundermech18@gmail.com.2harihari1003@gmail.com. ${ }^{3}$ rkvasan731@gmail.com.

${ }^{4}$ muthu.sakthivelvdm@gmail.com. ${ }^{5}$ cnaveenkumar88@gmail.com

\begin{abstract}
In recent material removal process, Conventional machining like drilling, milling, grinding etc can be replaced by Non traditional machining because of high surface finish, Minimum tool wear and excellent dimensional accuracy. Particularly for machining high hardened materials like ceramic, composites and super alloys Electrical discharge Machining (EDM) process is preferred. In this paper an attempt is made to machining of Aluminium nano composites. It is fabricated by melting Aluminium alloy 6061 in a crucible and stirred the preheating Multiwall carbon nanotubes (MWCNT) with different Wt\% using stir casting technique. Now 16 Experiments with varying three input parameters Current, Pulse On and Pulse Off having four level of factors were conducted. The output parameters can be measured by Surface Roughness value (SR), Material Removal rate (MRR) and Tool wear rate (TWR). From the Taguchi analysis, it is determined that MRR, TWR and SR gives good results when using copper electrode for machining of aluminum nano composite.
\end{abstract}

\section{Keywords: Aluminum Nano composites, EDM, MWCNT, and Taguchi design.}

\section{Introduction}

The history of EDM Machining Techniques goes as far back as the 1770s when it was discovered by an English Scientist. However, Electrical Discharge Machining was not fully taken advantage of until 1943 when Russian scientists learned how the erosive effects of the technique could be controlled and used for machining purposes. When it was originally observed by Joseph Priestly in 1770, EDM Machining was very imprecise and riddled with failures. Commercially developed in the mid 1970s, wire EDM began to be a viable technique that helped shape the metal working industry we see today. In the mid 1980s. The EDM techniques were transferred to a machine tool. This migration made EDM more widely available and appealing over traditional machining processes. The new concept of manufacturing uses non-conventional energy sources like sound, light, mechanical, chemical, electrical, electrons and ions. With the industrial and technological growth, development of harder and difficult to machine materials, which find wide application in aerospace, nuclear engineering and other industries owing to their high strength to weight ratio, hardness and heat resistance qualities has been witnessed. New developments in the field of material science have led to new engineering metallic materials, composite materials and high tech ceramics having good mechanical properties and thermal characteristics as well as sufficient electrical conductivity so that they can readily be machined by spark erosion. Non-traditional machining has grown out of the need to machine these exotic materials. The machining processes are nontraditional in the sense that they do not employ traditional tools for metal removal and instead they 


\section{www.rspsciencehub.com}

directly use other forms of energy. The problems of high complexity in shape, size and higher demand for product accuracy and surface finish can be solved through non-traditional methods. Currently, non-traditional processes possess virtually unlimited capabilities except for volumetric material removal rates, for which great advances have been made in the past few years to increase the material removal rates. As removal rate increases, the cost effectiveness of operations also increases, stimulating ever greater uses of non-traditional process. The Electrical Discharge Machining process is employed widely for making tools, dies and other precision parts.

EDM has been replacing drilling, milling, grinding and other traditional machining operations and is now a well-established machining option in many manufacturing industries throughout the world. And is capable of machining geometrically complex or hard material components, that are precise and difficult-to-machine such as heat treated tool steels, composites, super alloys, ceramics, carbides, heat resistant steels etc. being widely used in die and mold making industries, aerospace, aeronautics and nuclear industries. Electric Discharge Machining has also made its presence felt in the new fields such as sports, medical and surgical, instruments, optical, including automotive $R \& D$ areas.

\subsection{Introduction of EDM}

Before Electro Discharge Machining (EDM) is an electro-thermal non-traditional machining Process, where electrical energy is used to generate electrical spark and material removal mainly occurs due to thermal energy of the spark. EDM is mainly used to machine difficult-to-machine materials and high strength temperature resistant alloys. EDM can be used to machine difficult geometries in small batches or even on job-shop basis. Work material to be machined by EDM has to be electrically conductive

\subsection{Principle of EDM}

In this process the metal is removing from the work piece due to erosion case by rapidly recurring spark discharge taking place between the tool and work piece. Show the mechanical set up and electrical set up and electrical circuit for electro discharge machining.

\section{Literature Review}

Any project work could not be carried out without previous relevant efforts done. In our case we also have gone through many books, journals, reports, projects and paper presentation which helped us to proceed smoothly and in very sequential manner with lots of knowledge. Here is some literature mentioned to show our gratitude for their help. Dhar and Purohit [1] evaluates the effect of current (c), pulse-on time (p) and air gap voltage (v) on MRR, TWR, ROC of EDM with $\mathrm{Al}-4 \mathrm{Cu}-$ 6Si alloy-10 wt. \% SiCP composites. This experiment can be using the PS LEADER ZNC EDM machine and a cylindrical brass electrode of $30 \mathrm{~mm}$ diameter. And three factors, three levels full factorial design was using and analyzing the results. A second order, non-linear mathematical model has been developed for establishing the relationship among machining parameters. The significant of the models were checked using technique ANOVA and finding the MRR, TWR and ROC increase significant in a non-linear fashion with increase in current karthikeyan et .al [2] has presented the mathematical molding of EDM with aluminium-silicon carbide particulate composites. Mathematical equation is $Y=\mathrm{f}(V, I, T)$. And the effect of MRR, TWR, SR with Process parameters taken in to consideration were the current (I), the pulse duration (T) and the percent volume fraction of $\mathrm{SiC}(25 \mu$ size $)$. A three-level full factorial design was choosing. Finally, the significant of the models were checked using the ANOVA. The MRR was found to decrease with an increase in the percent volume of $\mathrm{SiC}$, whereas the TWR and the surface roughness increase with an increase in the volume of Sic.[3-7] Evolution the of effect of the EDM Current, electrode marital polarity, pulse duration and rotation of electrode on metal removal rate, TWR, and SR, and the EDM of Al-Sic with 20-25 vol. \% SiC, Polarity of the electrode and volume present of $\mathrm{SiC}$, the MRR increased with increased in discharge current and specific current it decreased with increasing in pulse duration. Increasing the speed of the rotation electrode resulted in a positive effect with MRR, TWR and better SR than stationary. The electric motor can be used to rotate the electrode (tool) AV belt as used to transmit he power from the motor to the electrode Optimization parameters for EDM drilling were also developed to summarize the effect of machining characteristic such as MRR, TWR and SR.[8-14]. 


\section{Experimental works}

In this chapter we are going to discuss about the experimental work which is consist about formation of the L-16 orthogonal array based on Taguchi design, orthogonal array is reduces the total on of experiment, in this experiment total 16 run. And Experimental set up, selection of work piece, tool design, and taking all the value and calculation of MRR (Material Removal Rate), SR (surface Roughness) and TWR (Tool Wear Rate).

For this experiment the whole work can be down by Electric Discharge Machine, (die-sinking type) with servo-head (constant gap) and positive polarity for electrode was used to conduct the experiments. Commercial grade EDM oil (specific gravity $=0.78$, freezing point $=92^{\circ} \mathrm{C}$ ) was used as dielectric fluid. With internal flushing of cu tool with a pressure of $0.230 \mathrm{kgf} / \mathrm{cm}^{2}$. Experiments were conducted with positive polarity of copper electrode. The pulsed discharge current was applied in various steps in positive mode.

\subsection{Power generator and control unit}

Power generator and control unit - The power supply control the amount of energy consumed. First, it has a time control function which controls the length of time that current flows during each pulse; this is called "on time." Then it is control the amount of current allowed to flow during each pulse. These pulses are of very short duration and are measured in microseconds. There is a handy rule of thumb to determine the amount of current a particular size of electrode should use: for an efficient removal rate, each square inch of electrode calls for 50 A. Low current level for large electrode will extend overall machine time unnecessarily. Conversely, too heavy a current load can damage the work piece of electrode.

\subsection{Mechanism of Tool wears}

Tool wear is an important factor because if affects dimensional accuracy and the shape produced. Tool wear is related to the melting point of the materials. Tool wear is affected by the precipitation of carbon from the hydrocarbon dielectric on the electrode surface during sparking. Also the rapid wear on the electrode edge was because of the failure of carbon to precipitate at difficult to reach regions of the electrode. TWR is expressed as the ratio of the difference of weight of the tool before and after machining to the machining time. Table 1 shows experiment runs according to Design of Experiments. The corresponding output of SR, MRR and TWR can be recorded for each experiment.

\subsection{Effect of Material Removal Rate:}

For any kind of machining process Material Removal Rate is considered tobe important machining characteristics, EDM is an electro thermal process, the material removal takes place by melting and evaporation. The fig 1 . Plot between MRR (g/cm3) Vs Current, Pulse On, and Pulse Off. Taguchi's analysis is used to interpret the relation between MRR and all input parameters. From the Fig.1. it is evident that MRR is optimum when Current reaches $15 \mathrm{~A}$, after the MRR value decreased. The $40 \mu \mathrm{s}$, the MRR is increased linearly in Pulse ON time. The MRR shows directly proportional to Pulse OFF time upto $6 \mu \mathrm{s}$, after the MRR value dropped.

\subsection{Effect of Surface Roughness:}

The fig.2.is plot between SR $(\mu \mathrm{m})$ Vs Current, Pulse On, Pulse Off. The influence of individual input parameters can be analyzed using Taguchi's method. Here SR is Optimum for 10A current, further SR value increases when current increases. The Pulse On time increases, value of SR also decreases upto $10 \mu \mathrm{s}$ after that SR increases further increase increasing of Pulse On time. The SR value in contradict with Pulse On time. Here Pulse Off time increases, then the SR value is increased and shows the optimum SR value at attained at $2 \mu \mathrm{s}$.

\subsection{Effect of Tool Wear Rate:}

The Effect of TWR vs Current, Pulse On and Pulse Off time shows in fig.3. The graph is plotted and interactions can be evaluated using Taguchi's Method. Tool wear is optimum at peak current of $5 \mathrm{~A}$. From the graph, when current value Increases, the tool wear gradually increases and both parameters are inversely proportional to each other. Further Pulse On time increases, tool wear rate also increases significantly. Hence minimum Pulse On time must be given to increase the Tool life. Pulse Off time also influences same like pulse on time for Tool wear rate. The Tool wear optimum at Pulse off time $2 \mu \mathrm{s}$, further increases the pulse off time, Tool wear also increased slightly. 


\section{Result and Discussion:}

Table.1.L16 Experimental Results

\begin{tabular}{|c|c|c|c|c|c|c|}
\hline \multirow{2}{*}{$\begin{array}{c}\text { Experiment } \\
\text { No }\end{array}$} & \multirow{2}{*}{$\begin{array}{l}\text { Current } \\
\text { (Amps) }\end{array}$} & \multirow{2}{*}{$\begin{array}{l}\text { Pulse } \\
\text { ON } \\
(\mu \mathrm{s})\end{array}$} & \multirow{2}{*}{$\begin{array}{l}\text { Pulse Off } \\
(\mu s)\end{array}$} & SR & MRR & TWR \\
\hline & & & & $(\mu \mathrm{m})$ & $\left(\mathrm{g} / \mathrm{cm}^{3}\right)$ & $\left(\mathrm{g} / \mathrm{cm}^{3}\right)$ \\
\hline 1. & 5 & 10 & 2 & 4.927 & 0.052 & 0.0002 \\
\hline 2. & 5 & 20 & 4 & 6.832 & 0.0905 & 0.0005 \\
\hline 3. & 5 & 30 & 6 & 8.421 & 0.115 & 0.0006 \\
\hline 4. & 5 & 40 & 8 & 7.329 & 0.2464 & 0.0022 \\
\hline 5. & 10 & 10 & 4 & 5.394 & 0.124 & 0.0046 \\
\hline 6. & 10 & 20 & 2 & 6.921 & 0.204 & 0.0004 \\
\hline 7. & 10 & 30 & 8 & 7.028 & 0.252 & 0.0008 \\
\hline 8. & 10 & 40 & 6 & 6.032 & 0.3598 & 0.3598 \\
\hline 9. & 15 & 10 & 6 & 4.868 & 0.4184 & 0.0024 \\
\hline 10. & 15 & 20 & 8 & 7.962 & 0.2532 & 0.0202 \\
\hline 11. & 15 & 30 & 2 & 6.702 & 0.3762 & 0.023 \\
\hline 12. & 15 & 40 & 4 & 7.568 & 0.1636 & 0.0186 \\
\hline 13. & 20 & 10 & 8 & 7.108 & 0.1646 & 0.0322 \\
\hline 14. & 20 & 20 & 6 & 7.838 & 0.3794 & 0.0334 \\
\hline 15. & 20 & 30 & 4 & 6.913 & 0.3348 & 0.0164 \\
\hline 16. & 20 & 40 & 2 & 8.172 & 0.2594 & 0.0198 \\
\hline
\end{tabular}

\subsection{Regression Equation:}

The regression equation is for MRR, SR \& TWR predicted from the minitab software shown in equation $12 \& 3$.

MRR $(\mathbf{g} / \mathbf{c m 3})=0.2371-0.1111$ Current $5-0.0021$ Current_10 +0.0658 Current_15+0.0475 Current_20 - 0.0473 Pulse On_10 - 0.0053 Pulse On_20+ 0.0324 Pulse On_30 + 0.0202 Pulse On_40 -

0.0142 Pulse Off_2- 0.0589 Pulse Off_4 + 0.0811 Pulse Off_6 - 0.0080 Pulse Off_8

SR $(\boldsymbol{\mu m})=6.876+0.001$ Current $55-0.532$ Current_10 - 0.101 Current_15 + 0.632 Current_20-

1.302 Pulse On_10+0.512 Pulse On_20 + 0.390 Pulse On_30 + 0.399 Pulse On_40- 0.195 Pulse Off_2 0.199 Pulse Off_4 - 0.086 Pulse Off_6 + 0.481 Pulse Off_8

TWR $((\mathbf{g} / \mathbf{c m 3}))=0.0334-0.0326$ Current_5 + 0.0580 Current_10 - 0.0174 Current_15-0.0080 Current_20 - 0.0236 Pulse On_10 - 0.0198 Pulse On_20-0.0232 Pulse On_ $\overline{3} 0+0.0667$ Pulse On_40 -

0.0226 Pulse Off_2- 0.0234 Pulse Off_4 + 0.0656 Pulse Off_6- 0.0196 Pulse Off_8 


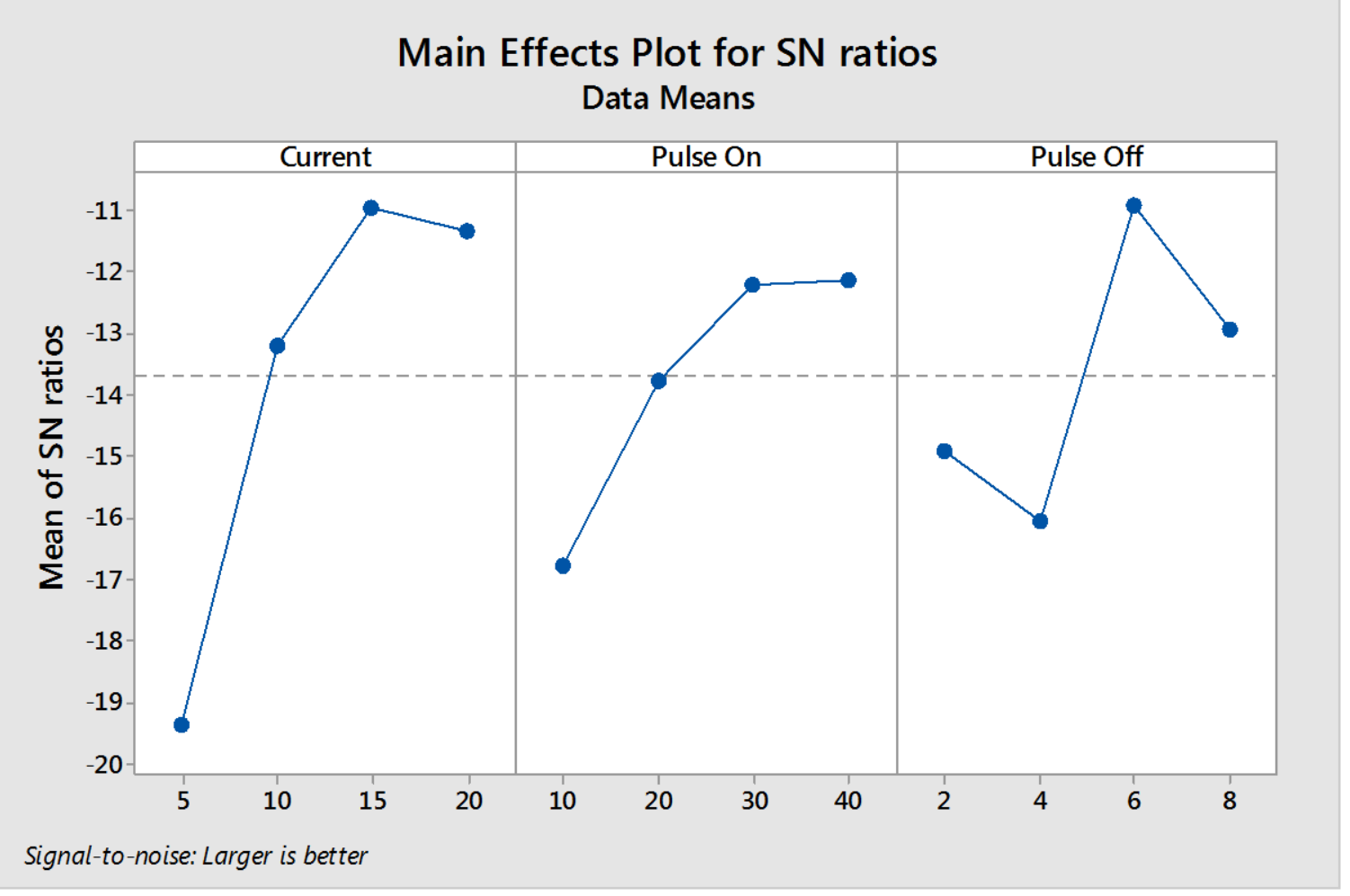

Fig : 1.MRR Vs Current, Pulse On, Pulse Off.

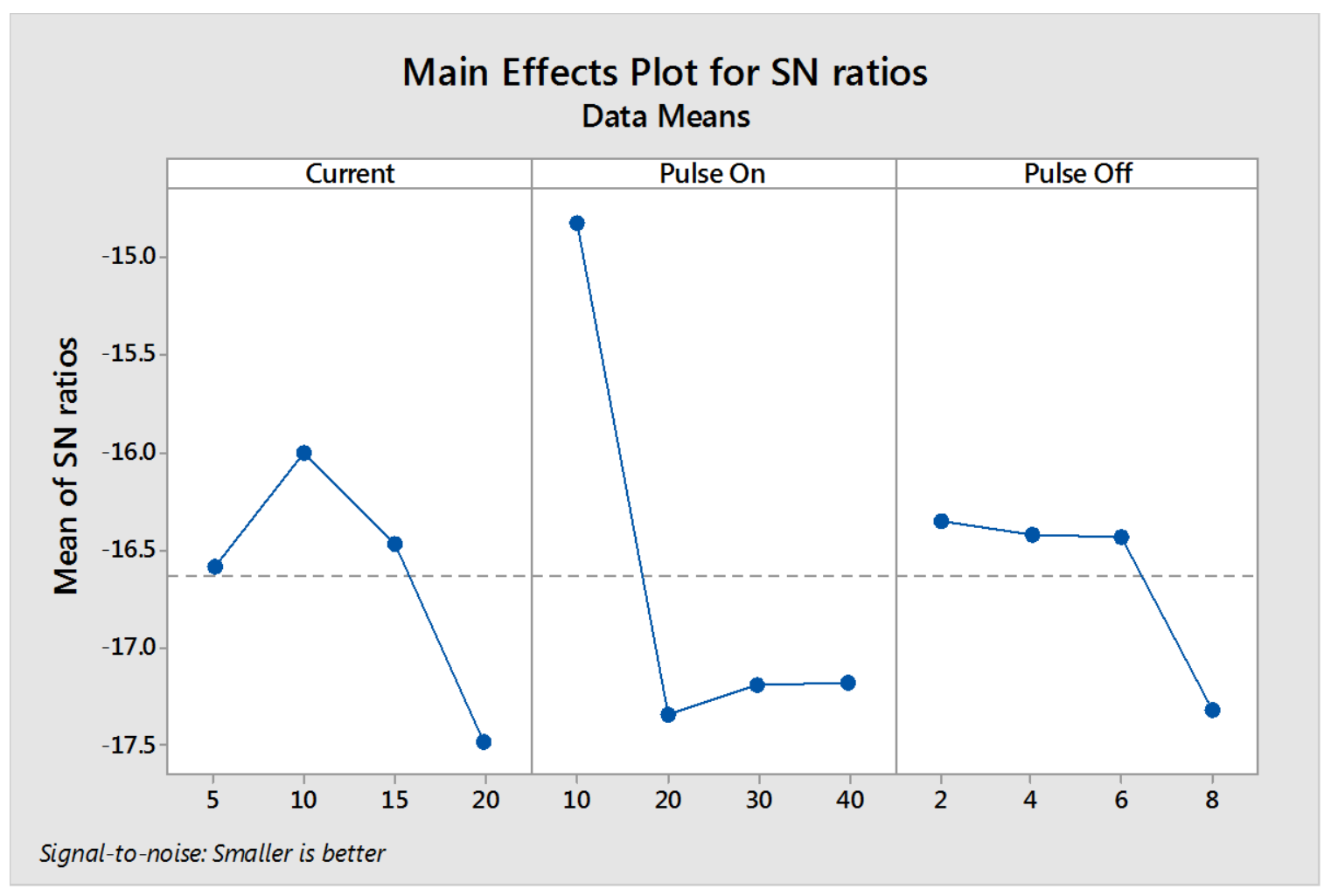

Fig : 2. SR Vs Current, Pulse On, Pulse Off. 


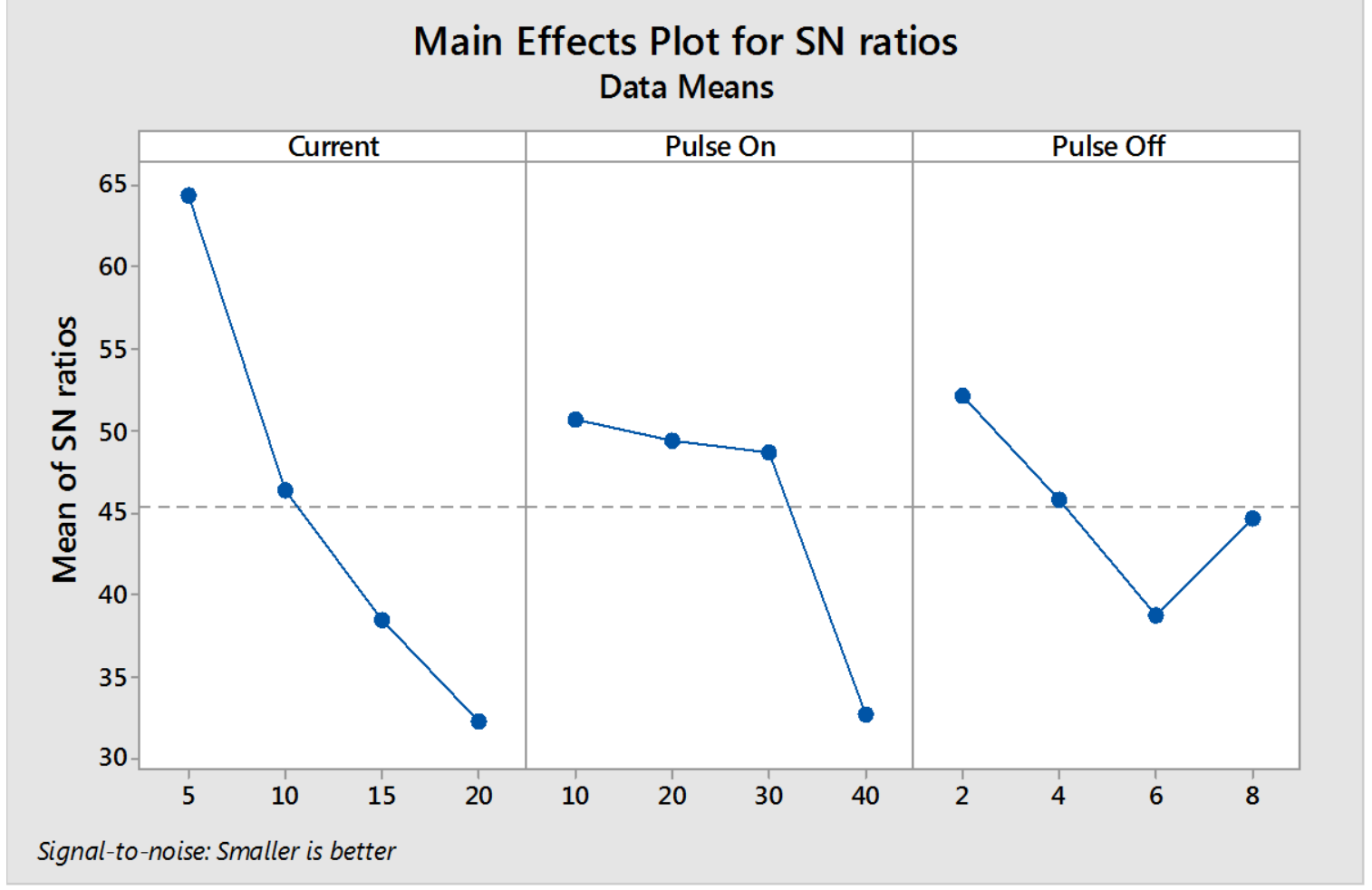

Fig : 3 TWR vs Current, Pulse On and Pulse Off time

\section{Conclusion}

From the experiments done, the following conclusion can be drawn. Aluminium and Multiwall Carbon Nanotubes can be fabricated by Stir casting technique. Further the machining is done by EDM with copper is used as a tool. There are three input parameters with Four level of factors can be taken to conduct 16 experiments and output parameters like TWR, MRR and SR values can be noted. Effect of Each parameter on TWR, SR and MRR can be plotted. From these graphs, MRR shows optimum at 15A current, $40 \mu$ s pulse On and $06 \mu$ s Pulse off value. Similarly, SR value is optimum for $10 \mathrm{~A}$ current, $10 \mu$ s Pulse On and $02 \mu$ s Pulse Off value. TWR shows good response when current value reaches $05 \mathrm{~A}, 10 \mu$ s Pulse On and $02 \mu \mathrm{s}$ Pulse Off value. The mathematical model also presented to predict the optimized process parameter to achieve high MRR and low SR and TWR.

\section{References}

[1]. Dhar, S., Purohit, Rr., Saini, R., Sharma, A. and Kumar, G.H., 2007. Mathematical modeling of electric discharge machining of cast $\mathrm{Al}-4 \mathrm{Cu}-6 \mathrm{Si}$ alloy-10 wt.\% sicp composites. Journal of Materials Processing Technology, 193(1-3), 24-29.

[2]. Karthikeyan R, Lakshmi Narayanan, P.R. and Naagarazan, R.S., 1999. Mathematical modeling for electric discharge machining of aluminiumsilicon carbide particulate composites.

Journal of Materials Processing Technology, 87(1-3), 59-63.

[3]. El-Taweel, T.A., 2009. Multi-response optimization of EDM with Al-Cu-Si-tic $\mathrm{P} / \mathrm{M}$ composite electrode. International Journal of Advanced Manufacturing Technology, 44(1-2),100-113.

[4]. Mohan, B., Rajadurai, A. and Satyanarayana, K.G., 2002. Effect of sic and rotation of electrode on electric discharge machining of Al-sic composite. Journal of Materials Processing Technology, 124(3), 297304.

[5]. Lin, y.-., Cheng, C.-., Su, B.-. and Hwang, L.-., 2006. Machining characteristics and optimization of 
machining parameters of SKH 57 highspeed steel using electrical-discharge machining based on Taguchi method. Materials and Manufacturing Processes, 21(8), 922-929.

[6]. J. Simao, H.G. Lee, D.K. Aspinwall, R.C. Dewes, and E.M. Aspinwall 2003.Workpiece surface modification using electrical discharge machining, 43 (2003) 121-128

[7]. Singh, P.N., Raghukandan, K., Rathinasabapathi, M. And Pai, B.C., 2004. Electric discharge machining of Al-10\% sicp as-cast metal matrix composites. Journal of Materials Processing Technology, 155-156(1-3), 1653-1657.

[8]. Soveja, A., Cicala, E., Grevey, D. And Jouvard, J.M., 2008. Optimisation of TA6V alloy surface laser texturing using an experimental design approach. Optics and Lasers in Engineering, 46(9), 671-678.

[9]. T. Pravin, C. Somu, R. Rajavel, M. Subramanian, P. Prince Reynold, Integrated Taguchi cum grey relational experimental analysis technique (GREAT) for optimization and material characterization of FSP surface composites on AA6061 aluminium alloys, Materials Today: Proceedings, 2020,

https://doi.org/10.1016/j.matpr.2020.02. 863.

[10]. R. Ranjith, C. Somu, G. Tharanitharan, Venkatajalapathi.T, Naveenkumar M, Integrated Taguchi cum Grey Relational Experimental Analysis (GREAT) for Optimization and Machining Characterization of Cryogenic Cooled AA6063 Aluminium Alloys, Materials Today: Proceedings, Volume 18, Part 7, 2019,Pages 3597- 605, https://doi.org/10.1016/j.matpr.2019.07. 291.

[11]. Yan, B.H., Wang, C.C., Chow, H.M. and Lin, Y.C., 2000. Feasibility study of rotary electrical discharge machining with ball burnishing for A12O3/6061 Al composite. International Journal of
Machine Tools and Manufacture, 40(10), 1403-1421.

[12]. Yan-Cherng Lin, Yuan-feng chen, Ching-tien Lin, AND Hsinn-jyh Tzeng Feasibility study of rotary electrical discharge machining with ball burnishing for Al2O3/6061Al composite 2008, vol.23: 391-399.

[13]. Multifunctional properties of carbon nanotube polymer composites' by HülyaCebeci, Roberto Guzman de Villoria, A. John Hart, Brian L. Wardle, 19 August 2009,U.S.A

[14]. Investigation of CNT reinforced aluminum matrix composite materials by Hansang. 